\title{
Prognostic impact of mRNA levels of osteopontin splice variants in soft tissue sarcoma patients
}

\author{
Antje Hahnel ${ }^{1^{*}+}$, Henri Wichmann ${ }^{1+}$, Thomas Greither ${ }^{2}$, Matthias Kappler ${ }^{3}$, Peter Würl ${ }^{4}$, Matthias Kotzsch' \\ Helge Taubert ${ }^{3,6,7}$, Dirk Vordermark ${ }^{1}$ and Matthias Bache ${ }^{1}$
}

\begin{abstract}
Background: It is well known that osteopontin (OPN) plays an important role in tumor progression and that a high OPN expression level in several tumor entities correlates with poor prognosis in cancer patients. However, little is known about the prognostic relevance of the OPN mRNA splice variants.

Methods: We analyzed the mRNA expression levels of different OPN splice variants in tumor tissue of 124 soft tissue sarcoma (STS) patients. Quantitative real-time PCR (qRT-PCR) was used to analyze the mRNA expression level of three OPN splice variants (OPN-a, -b and -c).

Results: The multivariate Cox's proportional hazard regression model revealed that high mRNA expression levels of OPN splice variants are significantly associated with poor prognosis in STS patients $(n=124)$. Women $(n=68)$ with high mRNA expression levels of OPN-a and OPN-b have an especially elevated risk of tumor-related death (OPN-a: $R R=3.0, P=0.01, C l=1.3-6.8 ; O P N-b: R R=3.4, P=0.01, C l=1.4-8.2)$. In particular, we found that high mRNA expression levels of OPN-b and OPN-c correlated with a high risk of tumor-related death in STS patients that received radiotherapy $(\mathrm{n}=52$; $\mathrm{OPN}-\mathrm{b}$ : $\mathrm{RR}=10.3, \mathrm{P}<0.01, \mathrm{Cl}=2.0-53.7$; $\mathrm{OPN}-\mathrm{c}$ : $\mathrm{RR}=11.4, \mathrm{P}<0.01, \mathrm{Cl}=2.2-59.3$ ).
\end{abstract}

Conclusion: Our study shows that elevated mRNA expression levels of OPN splice variants are negative prognostic and predictive markers for STS patients. Further studies are needed to clarify the impact of the OPN splice variants on prognosis.

\section{Background}

Osteopontin is a secreted phosphoprotein that plays an important role in tumor progression. It affects processes such as cellular growth, cell migration, invasion, metastasis and decay of the extracellular matrix [1]. Several studies showed that an increased OPN expression correlates with poor prognosis in cancer patients [2-4]. However, only a few studies have analyzed the importance of OPN for tumor progression in sarcomas. OPN protein expression level was shown to be elevated in tumor cells, and high OPN levels were associated with high tumor stage, tumor grade and poor survival in sarcoma patients [5-7]. Additionally, Bramwell et al. (2005) showed that OPN mRNA is also overexpressed in the tumor tissue of STS patients. In a previous study, we demonstrated that

\footnotetext{
* Correspondence: antje.hahnel@medizin.uni-halle.de

† Contributed equally

'Department of Radiotherapy, Martin-Luther-University of Halle-Wittenberg,

Dryanderstr.4, Halle (Saale) 06110, Germany

Full list of author information is available at the end of the article
}

higher OPN protein expression levels in tumor tissue and serum were associated with worse prognosis in STS patients [8].

Young et al. (1990) identified three splice variants of OPN, but their specific functions remained unclear. In addition to the full-length form osteopontin-a (OPN-a) with 7 exons, there are the splice variants osteopontin-b (OPN-b) and osteopontin-c (OPN-c) with deletions of exon 5 and exon 4, respectively. The first in vitro studies demonstrated a different impact of the OPN splice variants on cell migration, invasion, apoptosis and proliferation in various cancer cell lines [9-13]. Compared to normal tissue, the tumor tissues of different cancer entities express higher levels of OPN splice variants [10,12,14-18]. However, only one study, which investigates breast cancer patients, analyzed the prognostic impact of the OPN splice variants [15]. In the present study, we analyzed the prognostic relevance of the expression level of the three OPN splice variants $(\mathrm{OPN}-\mathrm{a},-\mathrm{b}$ and $-\mathrm{c})$ in the tumor tissue of 124 STS patients.

\section{C) Biomed Central}




\section{Methods}

Patients and tissue samples

We analyzed the frozen primary tumor samples of 124 STS patients and surrounding tissue of 15 STS patients by qRT-PCR for the mRNA expression of OPN splice variants (partially described in [8]). The clinical and histomorphological parameters of the STS patients are shown in Table 1 . In total, $50.8 \%$ of STS patients $(n=63)$ were still alive after an average follow-up time of 57.3 (range 9 -198) months, and $49.2 \%$ of STS patients $(\mathrm{n}=$ 61) died from tumor-related reasons after an average of 28.0 (range 2-201) months. The tumors were staged according to the Union for International Cancer Control (UICC) system. All patients gave their written informed

Table 1 Clinical and histomorphological data

\begin{tabular}{|c|c|c|c|c|c|c|c|}
\hline \multirow[t]{2}{*}{ Parameter } & \multirow[t]{2}{*}{ Total $(n=124)$} & \multicolumn{2}{|c|}{ OPN-a mRNA expression } & \multicolumn{2}{|c|}{ OPN-b mRNA expression } & \multicolumn{2}{|c|}{ OPN-c mRNA expression } \\
\hline & & low $(n=62)$ & high $(n=62)$ & low $(n=62)$ & high $(n=62)$ & low $(n=62)$ & high $(n=62)$ \\
\hline Sex & & \multicolumn{2}{|c|}{$P=0.02$} & \multicolumn{2}{|c|}{$P=0.10$} & \multicolumn{2}{|c|}{$P=0.37$} \\
\hline Male & 56 & 35 & 21 & 33 & 23 & 31 & 25 \\
\hline Female & 68 & 27 & 41 & 29 & 39 & 31 & 37 \\
\hline Histological subtype & & \multicolumn{2}{|c|}{$P=0.96$} & \multicolumn{2}{|c|}{$P=0.17$} & \multicolumn{2}{|c|}{$P=0.17$} \\
\hline Liposarcoma & 27 & 14 & 13 & 14 & 13 & 13 & 14 \\
\hline MFH/Fibrosarcoma & 38 & 17 & 21 & 14 & 24 & 14 & 24 \\
\hline NS & 15 & 8 & 7 & 9 & 6 & 9 & 6 \\
\hline RMS + LMS & 29 & 15 & 14 & 14 & 15 & 15 & 14 \\
\hline other STS & 15 & 8 & 7 & 11 & 4 & 11 & 4 \\
\hline Tumor grade & & \multicolumn{2}{|c|}{$P=0.03$} & \multicolumn{2}{|c|}{$P=0.05$} & \multicolumn{2}{|c|}{$P=0.03$} \\
\hline । & 16 & 6 & 10 & 6 & 10 & 4 & 12 \\
\hline$\|$ & 70 & 42 & 28 & 42 & 28 & 42 & 28 \\
\hline III & 37 & 13 & 24 & 14 & 23 & 16 & 21 \\
\hline Tumor stage & & \multicolumn{2}{|c|}{$P=0.37$} & \multicolumn{2}{|c|}{$P=0.43$} & \multicolumn{2}{|c|}{$P=0.33$} \\
\hline । & 15 & 7 & 8 & 7 & 8 & 5 & 10 \\
\hline$\|$ & 57 & 33 & 24 & 33 & 24 & 33 & 24 \\
\hline III & 40 & 18 & 22 & 17 & 23 & 19 & 21 \\
\hline IV & 12 & 4 & 8 & 5 & 7 & 5 & 7 \\
\hline Tumor localization & & \multicolumn{2}{|c|}{$P=0.29$} & \multicolumn{2}{|c|}{$P=0.26$} & \multicolumn{2}{|c|}{$P=0.30$} \\
\hline Extremities & 79 & 37 & 42 & 37 & 42 & 36 & 43 \\
\hline Thorax & 12 & 5 & 7 & 5 & 7 & 6 & 6 \\
\hline Head and neck & 4 & 1 & 3 & 1 & 3 & 1 & 3 \\
\hline Abdominal & 27 & 18 & 9 & 17 & 10 & 18 & 9 \\
\hline Other & 2 & 1 & 1 & 2 & 0 & 1 & 1 \\
\hline Recurrence & & \multicolumn{2}{|c|}{$P=1.00$} & \multicolumn{2}{|c|}{$P=1.00$} & \multicolumn{2}{|c|}{$P=1.00$} \\
\hline Yes & 55 & 28 & 27 & 28 & 27 & 27 & 28 \\
\hline No & 69 & 34 & 35 & 34 & 35 & 35 & 34 \\
\hline Lymph node status & & \multicolumn{2}{|c|}{$P=0.21$} & & 0.21 & & 0.03 \\
\hline No & 118 & 61 & 57 & 61 & 57 & 62 & 56 \\
\hline N1 & 6 & 1 & 5 & 1 & 5 & 0 & 6 \\
\hline Distant metastases & & & 0.28 & & 0.88 & & 0.88 \\
\hline MO & 45 & 25 & 20 & 23 & 22 & 23 & 2 \\
\hline M1 & 50 & 20 & 30 & 24 & 26 & 24 & 26 \\
\hline Evaluation not possible & 3 & 2 & 1 & 2 & 1 & 2 & 1 \\
\hline Radiation & & & 1.00 & & 0.86 & & 0.86 \\
\hline Yes & 58 & 29 & 29 & 30 & 28 & 30 & 28 \\
\hline No & 66 & 33 & 33 & 32 & 34 & 32 & 34 \\
\hline Chemotherapy & & & 0.74 & & 0.74 & & 0.74 \\
\hline Yes & 10 & 4 & 6 & 4 & 6 & 4 & 6 \\
\hline No & 114 & 58 & 56 & 58 & 56 & 58 & 56 \\
\hline
\end{tabular}

Abbreviations: MFH - malignant fibrous histiocytoma, NS - neurogenic sarcoma, RMS - rhabdomyosarcoma, LMS - leiomyosarcoma 
consent to the Institute of Pathology, University of Halle, Germany, and Department of Surgery 1, University of Leipzig, Germany. The study was approved by the Ethics Committee of the Medical Faculty of the Martin-LutherUniversity Halle-Wittenberg and is in compliance with the Helsinki Declaration.

\section{RNA preparation, cDNA synthesis and transcript analysis} by quantitative real-time PCR (qRT-PCR)

The total RNA of the frozen tissue samples was isolated by the Trizol method (Invitrogen, Karlsruhe, Germany), and the cDNA was prepared using the RevertAid ${ }^{\mathrm{TM}} \mathrm{H}$ Minus First Strand cDNA Synthesis Kit (Fermentas, St.Leon-Rot, Germany) according to the manufacturer's instructions. All qRT-PCR reactions were performed on a Rotorgene RG-6000 (LTF, Wasserburg, Germany) using the QuantiTect SYBRGreen PCR Kit (Fermentas). The primer sequences of the OPN splice variants and specific annealing temperatures are summarized in Table 2 (previously described in [14]). HPRT (hypoxanthine-guanine phosphoribosyltransferase) was used as a housekeeping gene (for standardization) and a marker for integrity of the cDNA. All methods were previously described in detail [8].

\section{Statistical analysis}

The statistical analysis was carried out using SPSS 17.0 (SPSS Inc., Chicago, IL, USA). Spearman's rho test was used for bivariate linear regression analyses. For survival analysis, the Kaplan-Meier method and the multivariate Cox's proportional hazard regression model were applied with appropriate adjustment to tumor type, tumor stage and tumor localization. We used a log-rank test to compare the survival curves of Kaplan-Meier analysis and to test for statistical differences. A two-tailed Fisher's exacttest or chi-square test was performed to determine the associations between mRNA expression level of OPN splice variants and different clinical parameters. A Wilcoxon signed-rank test was used to analyze the statistical differences of the 15 paired tumor and normal tissues. For survival analysis and comparison with clinical parameters, the cut-off values were set according to the median of
mRNA expression levels of OPN splice variants (Table 3). A probability $\geq 95 \%(\mathrm{P} \leq 0.05)$ was considered an indicator of a significant difference between mean values.

\section{Results and discussion}

mRNA expression levels of OPN splice variants in STS tissues

The analysis of mRNA expression levels of OPN splice variants in the tumor tissues of 124 STS patients reveals a median transcript ratio of 0.68 copies OPN-a mRNA/ copies HPRT mRNA (range: 9.30*10 $10^{-4}$-85.29), 0.49 copies OPN-b mRNA/copies HPRT mRNA (range: 0.00-17.64) and 0.082 copies OPN-c mRNA/copies HPRT mRNA (range: 0.00-4.03). Comparison of the OPN splice variants mRNA expression levels clearly showed that OPN-a and OPN-b are expressed at a distinctly higher level than OPN-c (both with $\mathrm{P}<0.01$ ). The lower expression level of OPN-c is consistent with the findings in hepatocellular carcinoma, breast cancer and mesothelioma $[12,15,16]$. Furthermore, using bivariate linear Spearman-Rho correlation, we found a significant correlation of the mRNA expression levels between all OPN splice variants $(r=0.84$ 0.95 , all with $\mathrm{P}<0.01$ ). Additionally, the mRNA expression level of total OPN and OPN splice variants show a weak correlation $(\mathrm{n}=65$, OPN-a: $\mathrm{r}=0.32, \mathrm{P}<0.01$; OPN-b: $\mathrm{r}=$ 0.30, $\mathrm{P}=0.02$; OPN-c: $\mathrm{r}=0.26, \mathrm{P}=0.04$ ).

In surrounding tissues of 15 STS patients we calculated a median transcript ratio of 0.66 copies OPN-a mRNA/ copies HPRT mRNA (range: $5.80 * 10^{-2}-30.19$ ), 0.19 copies OPN-b mRNA/copies HPRT mRNA (range: $7.20^{*} 10^{-3}$ 3.98) and 0.034 copies OPN-c mRNA/copies HPRT mRNA (range: $9.55^{*} 10^{-4}-0.67$ ). The median mRNA expression levels of OPN splice variants reveal that OPN$\mathrm{b}$ and OPN-c in paired tumor tissues are expressed on a higher level compared to surrounding tissues $(\mathrm{n}=15, \mathrm{p}=$ 0.07 and $\mathrm{p}=0.06$ ). Figure 1 demonstrates a 2.9 and 3.4fold increased mRNA expression level of OPN-b and OPN-c in tumor tissues. However, OPN-a mRNA expression level was not increased in tumor tissues (1.2-fold, $\mathrm{p}=0.80$ ). Several other studies confirm in tumor tissues a higher mRNA expression level of OPN splice variants

Table 2 Primers for quantitative real-time RT-PCR

\begin{tabular}{|c|c|c|c|c|c|}
\hline Gene & Primer & Sequence $5^{\prime} \rightarrow 3^{\prime}$ & & Localization & Annealing temperature \\
\hline \multirow[t]{2}{*}{ HPRT } & HPRT309 & 5'-TTGCTGACCTGCTGGATTAC-3' & sense & $391-410$ & $58^{\circ} \mathrm{C}$ \\
\hline & HPRT507 & 5'-CTTGCGACCTTGACCATCTT-3' & antisense & $633-652$ & \\
\hline \multirow[t]{2}{*}{ OPN-a } & OPN-a fw 323 & 5'-ATCTCCTAGCCCCACAGAAT-3' & sense & $323-342$ & $58^{\circ} \mathrm{C}$ \\
\hline & OPN-a rev 508 & 5'-CATCAGACTGGTGAGAATCATC-3' & antisense & $529-508$ & \\
\hline \multirow[t]{2}{*}{ OPN-b } & OPN-b fw 323 & 5'-ATCTCCTAGCCCCACAGAC-3' & sense & $323-341$ & $62^{\circ} \mathrm{C}$ \\
\hline & OPN-b rev 509 & 5'-AAAATCAGTGACCAGTTCATCAG-3' & antisense & $531-509$ & \\
\hline \multirow[t]{2}{*}{ OPN-C } & OPN-c fw 246 & 5'-TGAGGAAAAGCAGAATGCTG-3' & sense & $246-265$ & $58^{\circ} \mathrm{C}$ \\
\hline & OPN-c rev 377 & 5'-GTCAATGGAGTCCTGGCTGT-3' & antisense & 396-377 & \\
\hline
\end{tabular}

Sequences and localization of primers used in this study correspond to mRNA sequences of HPRT [Genbank: NM_000194.2], OPN-a [Genbank: NM_001040058.1], OPN-b [Genbank: NM_000582.2] and OPN-c [Genbank: NM_001040060.1] 
Table 3 Kaplan-Meier analyses and multivariate Cox's regression analyses

\begin{tabular}{|c|c|c|c|c|c|c|c|c|}
\hline \multirow[t]{2}{*}{ STS patients } & \multirow[t]{2}{*}{ OPN splice variant } & \multirow[t]{2}{*}{$\mathrm{n}$} & \multirow{2}{*}{$\begin{array}{c}\text { Median values } \\
\text { [copies OPN splice } \\
\text { variant mRNA/ } \\
\text { copies HPRT mRNA] }\end{array}$} & \multicolumn{2}{|c|}{ Kaplan-Meier analysis } & \multicolumn{3}{|c|}{ multivariate Cox's regression model } \\
\hline & & & & Survival [months] & $\mathbf{P}$ & RR & $\mathbf{P}$ & $\mathrm{Cl}$ \\
\hline \multirow[t]{6}{*}{ All } & OPN-a low & 62 & 0.68 & 90 & & & & \\
\hline & OPN-a high & 62 & & 71 & 1.7 & 1.7 & 0.06 & $1.0-3.0$ \\
\hline & OPN-b low & 62 & 0.49 & 117 & & & & \\
\hline & OPN-b high & 62 & & 66 & 0.13 & 2.1 & 0.02 & $1.2-3.6$ \\
\hline & OPN-c low & 62 & 0.08 & 94 & & & & \\
\hline & OPN-c high & 62 & & 81 & 0.38 & 1.8 & 0.04 & $1.0-3.1$ \\
\hline \multirow[t]{6}{*}{ Female } & OPN-a low & 34 & 0.83 & 116 & & & & \\
\hline & OPN-a high & 34 & & 53 & 0.08 & 3.0 & 0.01 & $1.3-6.8$ \\
\hline & OPN-b low & 34 & 0.58 & 102 & & & & \\
\hline & OPN-b high & 34 & & 42 & 0.13 & 3.4 & $<0.01$ & $1.4-8.2$ \\
\hline & OPN-c low & 34 & 0.09 & 92 & & & & \\
\hline & OPN-c high & 34 & & 46 & 0.50 & 2.3 & 0.07 & $0.9-5.4$ \\
\hline \multirow[t]{6}{*}{ RT patients } & OPN-a low & 26 & 0.65 & 80 & & & & \\
\hline & OPN-a high & 26 & & 76 & 0.04 & 3.5 & 0.07 & $0.9-13.0$ \\
\hline & OPN-b low & 26 & 0.42 & 147 & & & & \\
\hline & OPN-b high & 26 & & 55 & 0.05 & 10.3 & $<0.01$ & 2.0-53.7 \\
\hline & OPN-c low & 26 & 0.07 & 147 & & & & \\
\hline & OPN-c high & 26 & & 55 & 0.05 & 11.4 & $<0.01$ & $2.2-59.3$ \\
\hline
\end{tabular}

Association of the mRNA expression of OPN splice variants in different groups of patients (all STS patients, females and RT patients) with overall survival. The median values of OPN-a, OPN-b and OPN-c were used as cut-off points to divide the STS patients into two groups: one with high and one with low (reference group) OPN mRNA levels in tumor tissues

than in surrounding or normal tissues [19,20]. In agreement with our analysis, in breast cancer and ovarian cancer, especially OPN splice variants OPN-b and OPN-c are expressed on elevated mRNA levels compared to surrounding or normal tissues $[10,14,15,18]$.

\section{Bivariate linear analyses of mRNA expression levels of OPN splice variants with clinical and histomorphological parameters}

Examinations of the relation of mRNA expression levels of OPN splice variants with clinical and histomorphological parameters revealed a significant correlation of the mRNA expression level of OPN-a with sex and tumor grade (Table 1). More male patients have a low OPN-a mRNA expression level compared to female patients $(\mathrm{P}=0.02$, Table 1). Grade 3 tumors are strongly associated with high mRNA expression levels of OPN-a, OPN-b and OPN-c (P $=0.03, \mathrm{P}=0.05$ and $\mathrm{P}=0.03$, respectively). The mRNA expression levels of the OPN splice variants were also significantly higher in high-grade gliomas than in low-grade gliomas [9,17]. Recently, Patani et al. (2008) verified that the mRNA expression levels of OPN-b and OPN-c were also increased with higher tumor grade in breast cancer. Furthermore, we found that all patients with lymph node metastases had a significantly higher OPN-c mRNA expression level $(\mathrm{P}=0.03)$. It is well known that OPN-c mediates anchorage independence and tumor invasion $[10,21]$, which are crucial processes for the development of metastases. Several studies showed that OPN-c is expressed at higher levels in invasive tumor cells compared to noninvasive tumor cells $[13,14,17,21]$. Furthermore, it has been demonstrated in these studies that OPN-c influences the expression of several migration/invasion markers, such as MMP-2, MMP-9 and uPA, which promote tumor cell invasion. This is in accordance with the correlation we found between the OPN splice variants, the uPA, UPAR and PAI mRNA and the protein expression levels in STS (data not shown). Previously, we could show that the protein levels of UPA, UPAR and PAI in tumor tissue and serum are also associated with poor prognosis of STS patients [22]. However, we found no correlation between the mRNA expression level of OPN splice variants and the tumor stage, histological tumor subtype (Additional file 1), tumor localization or recurrence.

\section{mRNA expression levels of OPN splice variants and} disease-associated survival

We performed multivariate Cox's proportional hazard regression analysis to study the correlation between OPN splice variant levels and tumor-specific survival. 


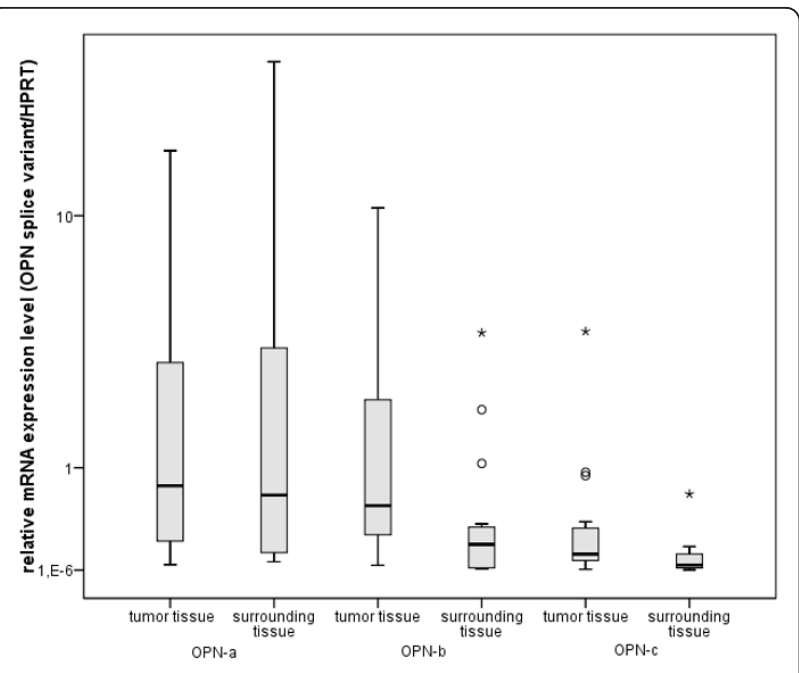

Figure 1 Comparison of mRNA expression of OPN splice variants in surrounding and tumor tissue. The boxplot shows the relative mRNA expression levels of OPN-a, OPN-b and OPN-c in tumor and paired surrounding tissues of 15 STS patients. The boxplot displays the median value of each data set, which is indicated by the centerline. The edges of the boxes represent the 25th percentile and 75th percentile. The 10th and 90th percentiles are marked through the horizontal lines outside the boxes. Circles and asterisks mark outliers ( 1.5 to 3 box lengths from the edge of the boxes) and far outliers (more than 3 lengths from the edge of the boxes).

The STS patients with high mRNA expression levels of the three OPN splice variants have a worse prognosis than those with low mRNA expression levels in their tumors. An elevated mRNA expression level of OPN-b or OPN-c is significantly correlated with a 2.1-fold or 1.8-fold increased risk of tumor-related death for STS patients, respectively $(\mathrm{P}=0.02, \mathrm{CI}=1.2-3.6 ; \mathrm{P}=0.04$, $\mathrm{CI}=1.0-3.1)$ (Table 3 ). The mRNA expression level of OPN-a shows an association trend with the prognosis of STS patients $(\mathrm{RR}=1.7, \mathrm{P}=0.06)$ (Table 3$)$. Additionally, STS patients had worst prognosis when all OPN splice variants are expressed on high mRNA levels (data not shown). A study on 15 adult STS patients found a significant increase of total OPN mRNA levels in tumor tissues compared to normal tissues [5]. Another study on 41 osteosarcoma patients reported that higher OPN mRNA levels were associated with a worse prognosis [23]. However, our preceding data of 68 STS patients revealed that mRNA expression level of whole OPN did not significantly correlate with prognosis [8]. Up to now, the prognostic relevance of the OPN splice variants was only determined for breast cancer patients. The breast cancer patients with high mRNA expression levels of OPN-b or OPN-c had significantly shorter survival times than those with low mRNA expression levels [15]. Because we found much lower mRNA expression levels of OPN-a in the tumors of male patients $(n=56)$ than in those of female patients $(n=68)$, we performed sex-specific survival analyses (Table 3 and Figure 2A.). A multivariate Cox's regression model also revealed that female STS patients have a significantly worse prognosis than male STS patients. The women with high OPN-a or OPN-b mRNA expression levels have a 3.0-fold ( $\mathrm{P}=$ $0.01, \mathrm{CI}=1.3-6.8)$ or 3.4 -fold $(\mathrm{P}<0.01, \mathrm{CI}=1.4-8.2)$ increased risk of tumor-related death, respectively. The different prognostic impact of the mRNA expression level in men and women is possibly caused by hormonal regulation of mRNA expression by female sex hormones or hormone receptors [24].

Therapy of STS patients comprises surgical removal of the tumor and treatment with radio- and/or chemotherapy. To investigate the prognostic impact of the mRNA expression level of OPN splice variants prior to radiotherapy, we analyzed STS patients who received a curative radiotherapy ( $\mathrm{n}=52$ ) (RT patients). In the Kaplan-Meier analysis, we found that the RT patients with low mRNA expression levels of all OPN splice variants have a significant survival benefit compared to those with high mRNA expression levels in their tumors $(\mathrm{P}<0.05$, Table 3$)$. In addition multivariate Cox's regression models revealed that RT patients with high mRNA expression levels of OPN-b and OPN-c have a 10.3-fold and 11.4-fold increased risk of tumor-related death, respectively $(\mathrm{P}<$ 0.01, CI $=2.0-53.7$; $\mathrm{P}<0.01, \mathrm{CI}=2.2-59.3$ ) (Figure 2B., Table 3$)$. In the STS patients who did not receive radiotherapy ( $n=62$ ), the mRNA expression level of the OPN splice variants had no prognostic importance (data not shown). Consequently, the inhibiting of OPN could provide an additional survival benefit for STS patients who are treated with radiotherapy. Similarly, Overgaard et al. (2005) found that high OPN plasma concentrations are associated with a poor prognosis in patients with head and neck cancer after radiotherapy [25]. Our in vitro study verified the association of OPN and radiotherapy and proved that the inhibition of OPN mRNA expression increases the radiosensitivity of the mamma carcinoma cells [26].

\section{Conclusions}

In the present study, we found for the first time that the mRNA expression levels of OPN-b and OPN-c were significantly correlated with the clinical outcome of STS patients. Our data demonstrate that female STS patients and RT patients with low mRNA expression levels of OPN splice variants have a distinct survival benefit. In fact, the different roles of the OPN splice variants in angiogenesis, cellular invasion, cancer progression, and metastasis are widely discussed in the literature $[14,17,18,21,27]$. Further studies are needed to clarify why OPN splice variants have different effects on the prognosis of cancer patients. 


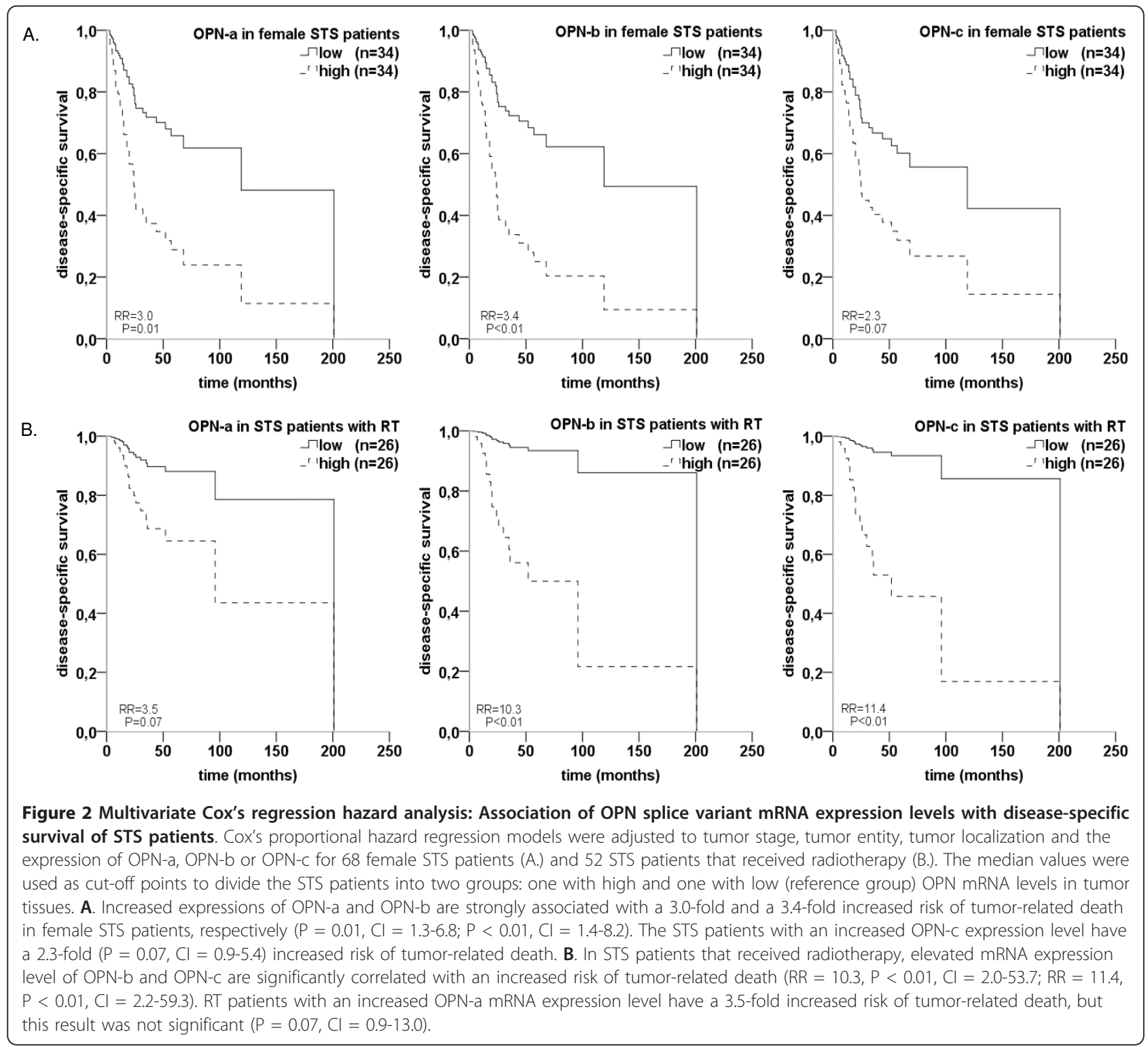

In summary, our data suggest that high expression levels of OPN splice variants are negative prognostic and predictive markers, particularly for female STS patients and those who receive curative radiotherapy. However, more data are necessary to evaluate the OPN splice variants in the clinical management of STS patients.

\section{Additional material}

Additional file 1: Median mRNA expression level of the OPN splice variants in the different histotypes of soft tissue sarcoma.

\section{Abbreviations}

RR: Relative risk of tumor-related death; P: Probability; Cl: 95\% confidence interval; r: Correlation coefficient

\section{Acknowledgements}

We would like to thank our colleagues from the Department of Radiotherapy for their contribution to this study and their continuous support. This work was supported by the Wilhelm Sander Stiftung (grant number: 2007.123.1 and 2007.123.2) and by the Wilhelm Roux program of BMBF/NBL3 (grant number: FKZ: 20/11 and 23/27). H.T.'s work was supported by the Deutsche Krebshilfe (No. 107590).

\section{Author details}

'Department of Radiotherapy, Martin-Luther-University of Halle-Wittenberg, Dryanderstr.4, Halle (Saale) 06110, Germany. ${ }^{2}$ Centre for Reproductive Medicine and Andrology, Martin-Luther-University of Halle-Wittenberg, ErnstGrube-Str. 40, Halle (Saale) 06907, Germany. ${ }^{3}$ Department of Oral and Maxillofacial Plastic Surgery, Martin-Luther-University of Halle-Wittenberg, Ernst-Grube-Str. 40, Halle (Saale) 06907, Germany. ${ }^{4}$ Department of General and Visceral Surgery, Diakoniekrankenhaus, Advokatenweg 1, Halle (Saale) 06114, Germany. ${ }^{5}$ Institute of Pathology, Dresden University of Technology, Fetscherstr.74, Dresden 01307, Germany. ${ }^{6}$ Clinic of Urology, FA University Hospital Erlangen, Glückstr. 6, Erlangen 91054, Germany. ${ }^{7}$ Nikolaus-Fiebiger- 
Center for Molecular Medicine, FA University Erlangen-Nürnberg, ErlangenNürnberg, Germany.

\section{Authors' contributions}

$\mathrm{AH}$ and $\mathrm{HW}$ designed the study, performed experimental procedures, analyzed the data and drafted the manuscript. TG, MKa, HT and DV aided in study design, analyzed the data and reviewed the manuscript. PW treated the patients, collected material and data and reviewed the manuscript. MKo performed experimental procedures, analyzed the data and reviewed the manuscript. MB designed the study, analyzed the data and drafted the manuscript. All authors read and approved the final manuscript.

\section{Competing interests}

The authors declare that they have no competing interests.

Received: 19 December 2011 Accepted: 2 April 2012

Published: 2 April 2012

\section{References}

1. Rangaswami H, Bulbule A, Kundu GC: Osteopontin: role in cell signaling and cancer progression. Trends Cell Biol 2006, 16:79-87.

2. Wai PY, Kuo PC: Osteopontin: regulation in tumor metastasis. Cancer Metastasis Rev 2008, 27:103-118.

3. Vordermark D, Said HM, Katzer A, Kuhnt T, Hansgen G, Dunst J, Flentje M, Bache M: Plasma osteopontin levels in patients with head and neck cancer and cervix cancer are critically dependent on the choice of ELISA system. BMC Cancer 2006, 6:207.

4. Bache M, Kappler M, Said HM, Staab A, Vordermark D: Detection and specific targeting of hypoxic regions within solid tumors: current preclinical and clinical strategies. Curr Med Chem 2008, 15:322-338.

5. Bramwell VH, Tuck AB, Wilson SM, Stitt LW, Cherian AK, Rorke SC, Al Katib W, Postenka CO, Chambers AF: Expression of osteopontin and HGF/ met in adult soft tissue tumors. Cancer Biol Ther 2005, 4:1336-1341.

6. Gaumann A, Petrow P, Mentzel T, Mayer E, Dahm M, Otto M, Kirkpatrick CJ, Kriegsmann J: Osteopontin expression in primary sarcomas of the pulmonary artery. Virchows Arch 2001, 439:668-674.

7. Sulzbacher I, Birner P, Trieb K, Lang S, Chott A: Expression of osteopontin and vascular endothelial growth factor in benign and malignant bone tumors. Virchows Arch 2002, 441:345-349.

8. Bache M, Kappler M, Wichmann H, Rot S, Hahnel A, Greither T, Said HM, Kotzsch M, Wurl P, Taubert H, Vordermark D: Elevated tumor and serum levels of the hypoxia-associated protein osteopontin are associated with prognosis for soft tissue sarcoma patients. BMC Cancer 2010, 10:132.

9. Saitoh Y, Kuratsu J, Takeshima H, Yamamoto S, Ushio Y: Expression of osteopontin in human glioma. Its correlation with the malignancy. Lab Invest 1995, 72:55-63.

10. He B, Mirza M, Weber GF: An osteopontin splice variant induces anchorage independence in human breast cancer cells. Oncogene 2006, 25:2192-2202.

11. Blasberg JD, Goparaju CM, Pass HI, Donington JS: Lung cancer osteopontin isoforms exhibit angiogenic functional heterogeneity. I Thorac Cardiovasc Surg 2010, 139:1587-1593.

12. Chae S, Jun HO, Lee EG, Yang SJ, Lee DC, Jung JK, Park KC, Yeom YI, Kim KW: Osteopontin splice variants differentially modulate the migratory activity of hepatocellular carcinoma cell lines. Int J Oncol 2009, 35:1409-1416.

13. Sullivan J, Blair L, Alnajar A, Aziz T, Ng CY, Chipitsyna G, Gong Q, Witkiewicz A, Weber GF, Denhardt DT, Yeo CJ, Arafat HA: Expression of a prometastatic splice variant of osteopontin, OPNC, in human pancreatic ductal adenocarcinoma. Surgery 2009, 146:232-240.

14. Mirza M, Shaughnessy E, Hurley JK, Vanpatten KA, Pestano GA, He B, Weber GF: Osteopontin-c is a selective marker of breast cancer. Int $J$ Cancer 2008, 122:889-897.

15. Patani N, Jouhra F, Jiang W, Mokbel K: Osteopontin expression profiles predict pathological and clinical outcome in breast cancer. Anticancer Res 2008, 28:4105-4110.

16. Ivanov SV, Ivanova AV, Goparaju CM, Chen Y, Beck A, Pass HI: Tumorigenic properties of alternative osteopontin isoforms in mesothelioma. Biochem Biophys Res Commun 2009, 382:514-518.

17. Yan W, Qian C, Zhao P, Zhang J, Shi L, Qian J, Liu N, Fu Z, Kang C, Pu P, You Y: Expression pattern of osteopontin splice variants and its functions on cell apoptosis and invasion in glioma cells. Neuro Oncol 2010, 12:765-775.

18. Tilli TM, Franco V, Robbs B, Wanderley J, Silva F, Mello KD, Viola JP, Weber GF, Gimba ER: Osteopontin-c splicing isoform contributes to ovarian cancer progression. Mol Cancer Res 2011, 9:280-293.

19. Jahns F, Wilhelm A, Jablonowski N, Mothes $H$, Radeva M, Wolfert A, Greulich KO, Glei M: Butyrate suppresses mRNA increase of osteopontin and cyclooxygenase-2 in human colon tumor tissue. Carcinogenesis 2011, 32:913-920.

20. Wang HH, Wang XW, Tang CE: Osteopontin expression in nasopharyngeal carcinoma: its relevance to the clinical stage of the disease. J Cancer Res Ther 2011, 7:138-142.

21. Takafuji V, Forgues M, Unsworth E, Goldsmith P, Wang XW: An osteopontin fragment is essential for tumor cell invasion in hepatocellular carcinoma. Oncogene 2007, 26:6361-6371.

22. Taubert H, Wurl P, Greither T, Kappler M, Bache M, Lautenschlager C, Fussel S, Meye A, Eckert AW, Holzhausen HJ, Magdolen V, Kotzsch M: Codetection of members of the urokinase plasminogen activator system in tumour tissue and serum correlates with a poor prognosis for soft-tissue sarcoma patients. Br J Cancer 2010, 102:731-737.

23. Dalla-Torre CA, Yoshimoto M, Lee CH, Joshua AM, de Toledo SR, Petrilli AS, Andrade JA, Chilton-MacNeill S, Zielenska M, Squire JA: Effects of THBS3, SPARC and SPP1 expression on biological behavior and survival in patients with osteosarcoma. BMC Cancer 2006, 6:237.

24. Miyajima J, Hayashi T, Saito K, lida S, Matsuoka K: The Interaction between female sex hormone receptors and osteopontin in a rat hyperoxaluric model. Kurume Med J 2010, 57:73-80.

25. Overgaard J, Eriksen JG, Nordsmark M, Alsner J, Horsman MR: Plasma osteopontin, hypoxia, and response to the hypoxia sensitiser nimorazole in radiotherapy of head and neck cancer: results from the DAHANCA 5 randomised double-blind placebo-controlled trial. Lancet Oncol 2005, 6:757-764.

26. Hahnel A, Wichmann $H$, Kappler M, Kotzsch M, Vordermark D, Taubert $H$, Bache M: Effects of osteopontin inhibition on radiosensitivity of MDAMB-231 breast cancer cells. Radiat Oncol 2010, 5:82.

27. Courter D, Cao H, Kwok S, Kong C, Banh A, Kuo P, Bouley DM, Vice C, Brustugun OT, Denko NC, Koong AC, Giaccia A, Le QT: The RGD domain of human osteopontin promotes tumor growth and metastasis through activation of survival pathways. PLoS One 2010, 5:e9633.

\section{Pre-publication history}

The pre-publication history for this paper can be accessed here: http://www.biomedcentral.com/1471-2407/12/131/prepub

doi:10.1186/1471-2407-12-131

Cite this article as: Hahnel et al:: Prognostic impact of mRNA levels of osteopontin splice variants in soft tissue sarcoma patients. BMC Cancer 2012 12:131.

\section{Submit your next manuscript to BioMed Central and take full advantage of:}

- Convenient online submission

- Thorough peer review

- No space constraints or color figure charges

- Immediate publication on acceptance

- Inclusion in PubMed, CAS, Scopus and Google Scholar

- Research which is freely available for redistribution

Submit your manuscript at www.biomedcentral.com/submit
Ciomed Central 